\title{
Mapping nursing language terms of Parkinson's disease
}

\author{
Mapeamento dos termos da linguagem de enfermagem na doença de Parkinson \\ Mapeo de los términos del lenguaje de enfermería en la enfermedad de Parkinson
}

Michelle Hyczy de Siqueira Tosin ${ }^{1}$, Débora Moraes Campos ${ }^{1}$, Luciana Blanco ${ }^{2}$, Rosimere Ferreira Santana ${ }^{3}$, Beatriz Guitton Renauld Baptista de Oliveira ${ }^{4}$

\author{
${ }^{1}$ Master's student, Universidade Federal \\ Fluminense, Niterói, RJ, Brazil. \\ ${ }^{2}$ Nurse, Sarah Network of Rehabilitation \\ Hospitals, Rio de Janeiro, RJ, Brazil. \\ ${ }^{3}$ Adjunct Professor, Department of Medical- \\ Surgical Nursing, Universidade Federal \\ Fluminense Niterói, RJ, Brazil. \\ ${ }^{4}$ Tenured Professor, Department of Nursing \\ Fundamentals and Administration, Universidade \\ Federal Fluminense, Niterói, RJ, Brazil.
}

\begin{abstract}
Objective: Implementing cross-mapping of Nursing language terms with the terminology of NANDA International, contained in records of patients with Parkinson's disease in rehabilitation. Method: Descriptive study of cross mapping, carried out in three steps. A simple random sample of 67 files of patients who participated in the rehabilitation in the period between March 2009 and April 2013. Results: We identified 454 terms of Nursing language that resulted in 54 diagnoses after cross-mapping, present in 11 of the 13 taxonomy domains. The most mapped diagnosis was "Impaired urinary elimination" (59.7\%), followed by "Urgent urinary incontinence" (55.2\%), "Willingness to self-control improved health" (50.7\%), "Constipation" (47.8\%) and "Compromised physical mobility" (29.9\%). Seven described terms were not mapped due to a corresponding defining characteristic being absent. Conclusion: It was possible to determine the profile of patients, as well as the complexity of nursing care in the rehabilitation of patients with Parkinson's disease.
\end{abstract}

\section{DESCRIPTORS}

Parkinson Disease; Classification; Nursing Diagnosis; Rehabilitation Nursing; Terminology.

\section{Corresponding author:}

Michelle Hyczy de Siqueira Tosin

Av. Embaixador Abelardo Bueno, 1500 - Barra

da Tijuca

CEP 22775-040 - Rio de Janeiro, RJ, Brazil

michellehyczy@gmail.com
Received: 08/04/2014

Approved: 03/19/2015 


\section{INTRODUCTION}

Parkinson's disease (PD) patient nursing care with those who are assisted in a neurological rehabilitation program can be considered complex work, both from signs and symptoms of the disease itself, as well as the mixed ideas inherent to the principles of rehabilitation ${ }^{(1-2)}$.

This disorder, which affects about five million people worldwide, was seen for a long time as a mobility disorder, which had the main features of classic motor symptoms resulting from dopamine depletion in specific brain regions. However, recent studies have shown that the clinical manifestations of PD are not only related to dopaminergic dysfunction occurring in the substantia nigra, they go beyond that, as the scattered impairment of the central nervous system favors the onset of symptoms considered motor and non-motor, and are characterized by bladder, bowel, sexual and mental dysfunction ${ }^{(1-3)}$.

These findings redirect the debate on PD pathophysiology and encourage discussion on the impact of these symptoms in the evolution of this disease, considered as progressive and multisystem ${ }^{(1,3)}$.

In this sense, the work of nurses in the context of rehabilitation of $\mathrm{PD}$ patients permeates aspects related to the limitations imposed by the disease. The rehabilitation nurse develops actions for prevention of injuries and complications, health promotion, and treatment of signs and symptoms. Their actions are focused on the affected individual in a broader, familiar, sociocultural and psycho-spiritual context, in order to contribute to the existing scientific knowledge for the multidisciplinary team in rehabilitation ${ }^{(2)}$.

However, nursing research on this topic is still incipient and regionalized in countries like USA, Canada and the $\mathrm{UK}^{(2,4-5)}$. In Brazil, the scientific production that deals with nursing care in the rehabilitation of patients with Parkinson's disease is still scarce.

Therefore, the use of standardized language for a nursing classification system as a resource for the transmission of scientific and technological information on this profession may influence knowledge in this area, because the use of this resource provides understanding for individuals who do not completely understand the language used, thereby reaching universal levels ${ }^{(6)}$.

Currently, among the existing nursing classification systems, there is the taxonomy proposed by NANDA-International (NANDA-I). This was created as a tool for diagnostic standardization, which can be used in various scenarios of nursing care, including rehabilitation ${ }^{(7)}$.

In this light, the use of NANDA-I Nursing Diagnoses enables the nurse to approach the patient with PD, facilitating the identification of care needs ${ }^{(2)}$. This is due so much to the ease of handling the range of taxonomy provided, since its structure is divided into 13 domains, 47 classes and 201 nursing diagnoses ${ }^{(8-9)}$. This dimensioning can encompass many aspects involved in the disease in a broader context, such as rehabilitation.

In this manner, the rehabilitation nurse is an active professional in the multidisciplinary team who plays an important role in the diagnosis, prevention and treatment of motor and non-motor disorders in Parkinson's disease patients. They should be knowledgeable about the standardization of language to normalise and improve their assistance, facilitate the exchange of information among scholars of the subject and support the provision of evidence-based care ${ }^{(2,6)}$.

Given the above, this study aimed to carry out crossmapping of the terms of Nursing language with the NANDA International terminology contained in records of patients with Parkinson's disease in rehabilitation.

\section{METHOD}

A descriptive cross-mapping study. This is a methodological tool used to compare data not yet standardized with the elected standardized language ${ }^{(10)}$.

The setting was the International Center for Neurorehabilitation and Neuroscience in the city of Rio de Janeiro (RJ), Brazil. In this center, children and adults with neurological sequelae due to congenital or acquired lesions of the central nervous system are attended to. The rehabilitation team is multidisciplinary, and the proposed treatment includes the monitoring of the patient's rehabilitation process and providing guidance to families, considering the particularities of each case.

In the study setting, the nurses' patient care is recorded in electronic medical records, by typing. In these records, nurses describe occurrences through terminology commonly used by the medical team. For this research, the authors considered excerpts of the developments that contain such terms in order to identify diagnostic contexts, since there was not a specific field/area for Nursing Diagnoses description in the electronic records system.

Since its opening in March 2009 until April 2013, 1,266 patients with the diagnosis of $\mathrm{PD}$ were admitted. Of these, 796 had nursing developments. For a sample definition, we chose to use, records that had five or more nursing developments as inclusion criterion, resulting in 167 records. Of these, in addition to the diagnosis of $\mathrm{PD}$, we discarded the records containing other associated medical diagnoses and those that characterized other Parkinson's syndromes, such as secondary Parkinson's. Thus, we obtained a total of 148 records.

Based on this population, we performed the sample calculation for descriptive studies with probability random sample, using the formula ${ }^{(11)}$ :

$$
\mathrm{n} 0=1 /(\mathrm{E} 0)^{2} \text { e } \mathrm{n}=\mathrm{N} \cdot \mathrm{n} 0 / \mathrm{N}+\mathrm{n} 0
$$

In this case, the following were considered: $\mathrm{N}=$ population size (148 records), E0 = tolerable sampling error (9\%), $\mathrm{n} 0=$ first approximation of the sample size (123 records) and $\mathrm{n}=$ sample size (67 records).

Thus, the sample was composed of 67 records, representing $45 \%$ of the total population, considering a sampling error of $9 \%$, and a $95 \%$ confidence interval. 335 records were analyzed in total.

For performing the data collection, we carried out a pilot test for the purpose of training and improving the three 
researchers on the data collection instrument, the records search and the mapping rules. After standardization, we proceeded collect and analyze the data from June 2013 to June 2014 in three stages: (1) extraction and standardization of terms; (2) separation and comparison of the non-standardized terms with standardized terms from NANDA-I and (3) evaluation and refinement of mapping.

In the first stage from August to November 2013, the three researchers conducted electronic extraction of information in its entirety for the composition of a database containing: patient data; medical diagnosis and the progression of the disease; the passage referring to the accurate contextual diagnosis, extracted from the nursing developments; and the extraction of terms of nursing language to indicate or exclude diagnostic hypotheses (defining characteristics or risk factors). For example, in the passage of nursing evolution that described Patient is continent, but has urinary urgency, the term urgency was highlighted by fragmentation of the evolution passage. In the passage, Patient maintains bowel movements every two days, with the presence of dry stools and the need of great effort to evacuate, the terms dry stools and effort to evacuate were highlighted.

These data were comprised in an Excel spreadsheet for Windows and subject to spelling correction, adequacy of tenses, and standardization of gender and number; also repetitions and synonyms of casual expressions that do not designate particular concepts were excluded.

In the second stage from December 2013 to May 2014, researchers proceeded to cross-map terms obtained in the previous step with the Nursing Diagnoses NANDA-I taxonomy. Therefore, the following rules of cross-mapping were used: map the context of the term and also map the meaning of words and not only the words ${ }^{(10)}$.

The terms of nursing language were compared with the defining characteristics or risk factors of NANDA-I. We adopted combination of analysis to categorize nursing terms. This was because when the term was found to be an exact match with the term of the classification system, this was categorized as an exact match; but when that term presented synonyms, similar concepts and related terms, it was categorized as a partial match. The terms that showed no resemblance to the classification system, or had no match, were exposed for analysis anyways.

To present the results of the analyzes, the exact and partial matches were considered to have the same value. In these two examples, the term "urgency," taken from the fragment of the evolution passage, considered as the diagnostic context, was considered to be an exact match with a defining characteristic of NANDA-I, which led to the diagnosis of Impaired urinary elimination. The terms dry stools and effort to evacuate were considered partial matches and correlated to the standard terms of NANDA-I of hard formed stools and effort to evacuate, which led to the diagnosis of constipation.

The data identified in this second stage were organized into a second Excel spreadsheet for Windows, which consisted of: title diagnosis; definition; standardized and non-standardized terms of NANDA-I, which corresponded to clinical confirmatory evidence for the presence of diagnosis.

The third step was carried out in June 2014, and consisted of the evaluation and refinement of cross-mapping. Therefore, the data obtained were analyzed by experts, two specialist nurses in the field of Nursing Classification and three in the area of Parkinson's diagnosis. For the selection of experts, we considered a minimum practical experience of 5 years or possessing title of $\mathrm{PhD}$ and experience in research on Nursing Classification Systems. The experts spoke about their agreement or otherwise regarding the relationship established by the authors between diagnostic titles, non-standardized terms and defining characteristics or risk factors of NANDA-I. This step was performed in two cycles: individual and group. New cycles were not necessary, since there was consensus among experts in the second cycle. This fact also exempted the need for analysis of statistical agreement.

The development of the study met the national and international standards of ethics in research involving human subjects (No. 691.310).

\section{RESULTS}

The sample consisted of $63 \%$ of male patients with a mean age of 69.3 years \pm 10 . The progression of Parkinson's disease ranged from 1 to 24 years, where $75 \%$ of them presented 1 to 8 years of $\mathrm{PD}$ evolution. With respect to nursing diagnoses, we identified 454 nursing language terms that resulted in 54 different NANDA-I diagnoses. The organization of Table 1 was based on the descending order of the presence of an isolated diagnosis. The calculation of the percentage rate was performed according to the total number of records analyzed.

Table 1 - NANDA International Nursing Diagnoses in patients with Parkinson's disease in the rehabilitation program - Rio de Janeiro, RJ, Brazil, 2014.

\begin{tabular}{|c|c|c|c|}
\hline NANDA-I Domain & Nursing Diagnoses according to NANDA International & $\mathbf{n}$ & $\%$ \\
\hline \multirow{8}{*}{$\begin{array}{l}\text { Elimination/ } \\
\text { Exchange }\end{array}$} & Impaired urinary elimination & 40 & 59.7 \\
\hline & Urge urinary incontinence & 37 & 55.2 \\
\hline & Constipation & 32 & 47.8 \\
\hline & Perceived Constipation & 12 & 17.9 \\
\hline & Reflex urinary incontinence & 7 & 10.4 \\
\hline & Stress urinary incontinence & 4 & 6.0 \\
\hline & Functional urinary incontinence & 4 & 6.0 \\
\hline & Overflow urinary incontinence & 4 & 6.0 \\
\hline
\end{tabular}


...continuation

\begin{tabular}{|c|c|c|c|}
\hline NANDA-I Domain & Nursing Diagnoses according to NANDA International & $\mathbf{n}$ & $\%$ \\
\hline & Readiness for enhanced urinary elimination & 2 & 3.0 \\
\hline & Bowel incontinence & 1 & 1.5 \\
\hline Subtotal & & 143 & 213.4 \\
\hline \multirow{3}{*}{ Health Promotion } & Readiness for enhanced health management & 34 & 50.7 \\
\hline & Risk-prone health behavior & 7 & 10.4 \\
\hline & Sedentary lifestyle & 3 & 4.5 \\
\hline Subtotal & & 44 & 65.7 \\
\hline \multirow{13}{*}{ Activity/Rest } & Impaired physical mobility & 20 & 29.9 \\
\hline & Risk for decreased cardiac tissue perfusion & 16 & 23.9 \\
\hline & Risk for ineffective cerebral tissue perfusion & 16 & 23.9 \\
\hline & Disturbed sleep pattern & 8 & 11.9 \\
\hline & Bathing self-care deficit & 5 & 7.5 \\
\hline & Impaired walking & 3 & 4.5 \\
\hline & Readiness for enhanced sleep & 3 & 4.5 \\
\hline & Dressing self-care deficit & 2 & 3.0 \\
\hline & Impaired transfer ability & 2 & 3.0 \\
\hline & Toileting self-care deficit & 2 & 3.0 \\
\hline & Sleep deprivation & 1 & 1.5 \\
\hline & Impaired bed mobility & 1 & 1.5 \\
\hline & Ineffective peripheral tissue perfusion & 1 & 1.5 \\
\hline Subtotal & & 80 & 119.4 \\
\hline \multirow{6}{*}{$\begin{array}{l}\text { Perception/ } \\
\text { Cognition }\end{array}$} & Impaired verbal communication & 10 & 14.9 \\
\hline & Impaired memory & 8 & 11.9 \\
\hline & Disturbed auditory sensory perception & 4 & 6.0 \\
\hline & Chronic confusion & 3 & 4.5 \\
\hline & Ineffective impulse control & 3 & 4.5 \\
\hline & Acute confusion & 1 & 1.5 \\
\hline Subtotal & & 29 & 43.3 \\
\hline \multirow{2}{*}{$\begin{array}{l}\text { Safety/ } \\
\text { protection }\end{array}$} & Risk for falls & 10 & 14.9 \\
\hline & Impaired skin integrity & 3 & 4.5 \\
\hline Subtotal & & 13 & 19.4 \\
\hline \multirow{9}{*}{ Nutrition } & Impaired swallowing & 9 & 13.4 \\
\hline & Risk for deficient fluid volume & 7 & 10.4 \\
\hline & Imbalanced nutrition: less than body requirements & 5 & 7.5 \\
\hline & Deficient fluid volume & 4 & 6.0 \\
\hline & Readiness for enhanced nutrition & 2 & 3.0 \\
\hline & Imbalanced nutrition: more than body requirements & 2 & 3.0 \\
\hline & Readiness for enhanced fluid balance & 1 & 1.5 \\
\hline & Risk for excess fluid volume & 1 & 1.5 \\
\hline & Excess fluid volume & 1 & 1.5 \\
\hline Subtotal & & 32 & 47.8 \\
\hline \multirow{2}{*}{ Comfort } & Social isolation & 9 & 13.4 \\
\hline & Chronic pain & 8 & 11.9 \\
\hline Subtotal & & 17 & 25.4 \\
\hline Life principles & Non-compliance & 7 & 10.4 \\
\hline Subtotal & & 7 & 10.4 \\
\hline \multirow{3}{*}{$\begin{array}{l}\text { Coping/Stress } \\
\text { Tolerance }\end{array}$} & Chronic sorrow & 4 & 6.0 \\
\hline & Caregiver stress overload & 3 & 4.5 \\
\hline & Anxiety & 3 & 4.5 \\
\hline
\end{tabular}

continued... 
...continuation

\begin{tabular}{|c|c|c|c|}
\hline NANDA-I Domain & Nursing Diagnoses according to NANDA International & $\mathbf{n}$ & $\%$ \\
\hline & Ineffective coping & 2 & 3.0 \\
\hline & Fear & 1 & 1.5 \\
\hline Subtotal & & 13 & 19.4 \\
\hline \multirow{2}{*}{$\begin{array}{l}\text { Role } \\
\text { Relationship }\end{array}$} & Interrupted family processes & 2 & 3.0 \\
\hline & Dysfunctional family processes & 1 & 1.5 \\
\hline Subtotal & & 3 & 4.5 \\
\hline Sexuality & Sexual dysfunction & 1 & 1.5 \\
\hline Subtotal & & 1 & 1.5 \\
\hline
\end{tabular}

Note: $(n=67)$.

However, seven diagnostic contexts were identified as described in 38 records, but were not mapped due to the absence of a corresponding defining characteristic in the taxonomy. These are described in Table 2.

Table 2 - Diagnosis contexts identified in Parkinson's disease patient records which could not be mapped in NANDA International Rio de Janeiro, RJ, Brazil, 2014.

\begin{tabular}{lc}
\hline Diagnosis contexts identified in the records & Repetitions \\
\hline Independent for Activities of Daily Living & 16 \\
Independent and secure walking & 9 \\
Change in the standard of handwriting & 4 \\
Efficient swallowing & 4 \\
Preserved mood/cognition & 3 \\
Preserved renal function & 2 \\
\hline Total & 38 \\
\hline
\end{tabular}

\section{DISCUSSION}

The sample characteristics of this research corroborate studies that show that Parkinson's disease more often affects men, especially in the age group above 60 years ${ }^{(12-13)}$. Regarding the duration of the disease, there is increasing evidence that the progression is not linear and is directly related to individual aspects ${ }^{(13)}$. These range from genetic traits to the age of onset and the profile of symptoms. Thus, individuals with PD can, a different way, live with this disease for up to 40 years ${ }^{(13)}$, which requires the rehabilitation nurse to have in-depth and detailed knowledge to work with this population.

Our results show that although the majority of individuals find themselves in a shorter course of the disease, the variability of nursing diagnoses was not lower. We observed that these are spread over almost all areas of NANDA-I, showing the magnitude of the approached aspects and related to PD, which manifests itself with a variety of both physiological and biopsychosocial signs and symptoms ${ }^{(2,9)}$. They also show the complexity of the clinical judgment of the rehabilitation nurses who work in this area.

With regard to the most mapped nursing diagnoses, the results of this research show the predominance of diagnoses related to non-motor symptoms of Parkinson's disease. These results converge with studies that show that, among the non-motor symptoms, constipation and urinary bladder changes are the most present, affecting $70-80 \%$ and $38-71 \%$ of patients, respectively ${ }^{(14-15)}$. In the present study, we can observe the reversal of the prevalence of these symptoms, which makes it important to consider the peculiarities that make up the population.

Despite that the non-motor symptoms of PD are not the most mapped in this study, those related to motor symptoms of the disease were notably present. In the nursing context of neurological rehabilitation, impaired physical mobility is an emphasized aspect in the evaluation.

It is known that the emergence of one or more motor symptoms is common with $\mathrm{PD}$, such as rigidity, bradykinesia, postural instability and resting tremors, which lead to loss of the individual's functional capacity ${ }^{(13)}$. Therefore, we highlight the diagnoses related to the execution deficit in Activities of Daily Living, such as: Impaired physical mobility, Impaired bed mobility, Bathing self-care deficit, Impaired walking, Dressing self-care deficit, Impaired transfer ability and Risk of falls, which were recorded from the sum of the data in $64 \%$ of records.

Thus, the rehabilitation nurse must be aware of issues that directly interfere in the functional capacity and quality of life of the individual, identifying the proper use of medications and satisfactory therapeutic response, presence of motor fluctuations, changes in gait and balance ${ }^{(1)}$. It should also be noted that motor symptoms are not the only deficiencies which can impair an individual's ability to perform activities of daily life. In this sense, quantifying the degree of cognitive and/or physical demand to complete a specific task are functional measures needed in this population, and this information directly influences decisions on rehabilita- 
tion, care needs, treatment plans and the education of the caregiver/family ${ }^{(16)}$.

Mobility changes have also evaluated the risk of falls, which can be enhanced by postural instability that is recognized as a classic motor symptom of PD. A study showed that falls occurred with $48 \%$ of patients with PD, and $24 \%$ of these fell more than once ${ }^{(17)}$. The data from this study show that the subject was identified in the nursing developments, however, the apparent presence compared to the literature suggests the need for greater emphasis in the nurse's search for this diagnosis in the patient's medical history.

To a lesser extent, other diagnoses identified in this study were in different areas of NANDA-I. Among them, we highlight Impaired swallowing and Risk for deficient fluid volume. These are diagnoses that may or may not be related to each other, since the change of swallowing capacity can lead the individual to restricting their water consumption. The literature encourages the intake of at least eight glasses of fluid a day, including juices and water, among others, for the maintenance of health and prevention of complications, such as constipation and kidney failure ${ }^{(18)}$.

On the other hand, swallowing disorders and oropharyngeal dysphagia are observed more frequently in patients with more advanced disease. In the literature, the prevalence of dysphagia varies from 18.5 to $100 \%{ }^{(19)}$. The pathological mechanisms of oropharyngeal dysphagia in PD are not very clear. In studies, they have been related to dysautonomia, which is considered a change of variable severity and complex pathophysiology that leads to neuronal changes in the sympathetic preganglionic route ${ }^{(1)}$.

For the diagnosis Impaired verbal communication, it is known that among the bulbar symptoms present in PD, dysarthria and hypophonia are changes resulting from bradykinesia and orofacial and laryngeal rigidity ${ }^{(13)}$. These changes are characterized by reducing the volume and intensity of voice, making it dull and hesitant, and speaking in short sentences. Other changes may be related to the rate of speech, characterized by palilalia and stuttering ${ }^{(13)}$. Therefore, this stresses the need for nurses to characterize this symptom to the patient for diagnosis, which will culminate in the development of the most appropriate and assertive care plan.

It was also observed in this study that chronic pain was a frequent complaint. Among the main causes of pain with $\mathrm{PD}$, we can mention musculoskeletal pain occurring as a consequence of rigidity, dystonia; and central pain caused by off or by comorbidities so common in these patients ${ }^{(13)}$. Thus, its cause is considered multifactorial, and along with motor symptoms can have fluctuating aspects. Its causes and conditions must be investigated at each nursing consultation, especially if there is a protocol of care present that considers the standardized language in its content.

The complaint of sexual dysfunction, described in one medical record, had the defining characteristic in agreement with NANDA-I as a perceived change in sexual arousal, which was mapped by crossing with the term hypersexuality. Compounding the group of non-motor symptoms, behavioral alterations caused by dopamine disregulation can be characterized by hypersexuality, compulsive jealousy, dys- phoria, gambling, among others ${ }^{(13)}$. When considering the rehabilitation program, attention to this diagnosis becomes necessary for interventionist actions that require team decision making together, because in this case there is important discussion between the nurse and the medical team for medical setting, and the psychology team for guidance on the management of symptoms ${ }^{(2,12,20)}$.

Likewise, we highlight the changes in memory, which are also considered non-motor symptoms and are related to the more advanced stages of PD. In these stages, patients can present neuropsychiatric symptoms such as depression, cognitive impairment and visual hallucinations ${ }^{(20)}$. The influence of some drugs used in PD control is also expected, leading to a worsening of these symptoms ${ }^{(20)}$. Thus, family guidance for the management of symptoms and discussion with the medical team for reassessment of drug therapy is essential to the development of the rehabilitation plan of care based on familiar practice ${ }^{(2)}$.

But even if family training is an important resource in the rehabilitation, the presence of nursing diagnoses Dysfunctional family processes and Interrupted family processes lead us to the need for prior analysis of the family situation. In direct interrelation with the previous diagnosis, in this study we observed that cognitive/behavioral worsening of PD patients led to a change in family dynamics due to the change of patient participation in decision-making. Often this led to deterioration and conflict in family relationships. The term Caregiver stress overload, quoted from the domain Coping/Stress Tolerance, is directly related to these factors. Socioeconomic changes, arising from the reversal of roles in the family structure should be taken into account in the rehabilitation program for that patient/family ${ }^{(4)}$.

In this context, the multidisciplinary approach to rehabilitation aimed at family guidance for the management and the medical setting in order to minimize the manifested symptoms is extremely important ${ }^{(2)}$. Similarly, family orientation for the search of legal resources and public policy in support of patients with PD and disabilities can provide ways of organizing the family system ${ }^{(4)}$.

For the diagnosis Social isolation, this discussion highlights those of motor complications and even other non-motor symptoms of DP such as urinary incontinence, gastrointestinal dysfunction, orthostatic hypotension and cognitive impairment may negatively interfere in the social function of patients, thus creating social isolation ${ }^{(4)}$. Another important variable related to social isolation is depression, which in PD patients may be related to an imbalance of neurotransmitters and the finding of functional and cognitive limitations imposed by the disease ${ }^{(1)}$.

In view of these aspects, the pursuit of the rehabilitation nurse for the diagnosis Readiness for enhanced health management becomes important not only to the population of patients with Parkinson's disease, but for all in the context of rehabilitation. The concepts and principles of rehabilitation predict health promotion, disease prevention, reduction of deficiency, disability and handicap ${ }^{(2)}$. Thus, the existing potential in the individual are restored.

Patient recognition facing their capabilities is one of the biggest challenges of rehabilitation that, in most cases, oc- 
curs when an individual is focused on their limitations and is considered passive to the treatment. Thus, identifying the need to provide support to the individual is an essential part of the rehabilitation process so that they are willing to take back control of their life and their health.

In this sense, the presence of the diagnosis Non-compliance shows how challenging the role of the rehabilitation nurse is. In this study, we mainly observed a low compliance to proper drug therapy and, in most cases, self-medication was present. It is known that the patient experiences an improvement in their motor symptoms after taking antiParkinson medication. In some cases, the more prolonged time it takes to take this medication, the lower its effect on the central nervous system and, consequently, the less time the drug will have an effect ${ }^{(13)}$.

Therefore, patients tend to reduce the interval of drug intake throughout the development of the disease, and many do so without medical supervision. However, studies show that, as part of the non-motor symptoms of PD, behavioral changes may be present and the misuse / abuse of dopaminergic drugs may contribute to such changes, characterizing what is called dopamine disregulation ${ }^{(13)}$.

Thus, it is important to identify this change to prevent future complications, and the nursing staff that works directly in the control and guidance of the correct use of medicines can strongly contribute to the multidisciplinary health team in detecting this alteration ${ }^{(21)}$.

The presence of diagnoses related to health promotion is noteworthy as to diagnoses identified in the nursing developments that were not amenable to mapping with the NANDA-I taxonomy. This was due to the fact that they were considered diagnoses that cannot be changed and are therefore not subject to corrective interventions, but preventive.

The records showed that nurses search for signs and symptoms that may influence the individual's functional capacity to perform their Activities of Daily Living, such as walking, swallowing, cognition, among others. However, even in the absence of such signs and symptoms, they left registered information in order to longitudinally monitor the patient that lives with a progressive disease of fluctuating character.

\section{CONCLUSION}

The cross-mapping identified the terms of nursing language and compared them with the NANDA-I classification system. In the categorization of 54 diagnoses found, there was a greater presence of non-motor symptoms of DP, especially those related to urinary function and bowel function. Among these, Impaired urinary elimination and Constipation were present in $59.7 \%$ and $47.8 \%$ of the records analyzed, respectively.

The motor symptoms related to patient's mobility capacity have also been described, and of these, Impaired physical mobility was the most mapped (29.9\%). But in this same category, some diagnoses were not conducive to mapping, which is a limitation of this study.

The main difficulty for this research was related to its analysis, as is noted by the lack of studies that relate the symptoms of PD to nursing diagnoses. Even before that, the findings point to the complexity of care provided in the rehabilitation of patients with Parkinson's, and reinforces the importance of nursing language standardization for scientific and professional advancement.

\section{RESUMO}

Objetivo: Realizar o mapeamento cruzado dos termos da linguagem de Enfermagem, com a terminologia da NANDA Internacional, contidos em prontuários de pacientes com doença de Parkinson em reabilitação. Método: Estudo descritivo, de mapeamento cruzado, executado em três etapas. Amostra aleatória simples constituída de 67 prontuários de pacientes que participaram da reabilitação no período entre março de 2009 e abril de 2013. Resultados: Foram identificados 454 termos da linguagem de Enfermagem que, após o mapeamento cruzado, culminaram em 54 diagnósticos, presentes em 11 dos 13 domínios da taxonomia. O diagnóstico mais mapeado foi "Eliminação urinária prejudicada" (59,7\%), seguido por "Incontinência urinária de urgência" (55,2\%), "Disposição para autocontrole da saúde melhorada" (50,7\%), "Constipação" (47,8\%) e "Mobilidade física prejudicada" (29,9\%). Sete termos descritos não foram mapeados devido à inexistência de característica definidora correspondente. Conclusão: Foi possível determinar o perfil dos pacientes, assim como a complexidade do cuidado de enfermagem na reabilitação de pacientes com doença de Parkinson.

\section{DESCRITORES}

Doença de Parkinson; Classificação; Diagnóstico de Enfermagem; Enfermagem em Reabilitação; Terminologia.

\section{RESUMEN}

Objetivo: Realizar el mapeo cruzado de los términos del lenguaje de Enfermería, con la terminología de NANDA Internacional, contenidos en fichas clínicas de pacientes con enfermedad de Parkinson en rehabilitación. Método: Estudio descriptivo, de mapeo cruzado, llevado a cabo en tres etapas. Muestra aleatoria simple constituida de 67 fichas clínicas de pacientes que participaron de la rehabilitación en el período entre marzo de 2009 y abril de 2013. Resultados: Fueron identificados 454 términos del lenguaje de Enfermería que, tras el mapeo cruzado, culminaron en 54 diagnósticos, presentes en 11 de los 13 dominios de la taxonomía. El diagnóstico más mapeado fue "Eliminación urinaria perjudicada" (59,7\%), seguido de "Incontinencia urinaria de urgencia" (55,2\%), "Disposición para autocontrol de la salud mejorada" (50,7\%), "Estreñimiento" (47,8\%) y "Movilidad física perjudicada" (29,9\%). Siete términos descritos no fueron mapeados en virtud de la no existencia de característica definidora correspondiente. Conclusión: Fue posible determinar el perfil de los pacientes, así como la complejidad del cuidado de enfermería en la rehabilitación de pacientes con enfermedad de Parkinson.

\section{DESCRIPTORES}

Enfermedad de Parkinson; Clasificación; Diagnóstico de Enfermería; Enfermería em Rehabilitación; Terminología. 


\section{REFERENCES}

1. Olanow CW, Schapira AH. Therapeutic prospects for Parkinson disease. Ann Neurol. 2013;74(3):337-47.

2. Young-Mason J. The fine art of caring: people with Parkinson disease and their care partners. Clin Nurse Spec. 2015;29(2):121-2.

3. Berg D, Postuma RB, Bloem B, Chan P, Dubois B, Gasser T, et al. Time to redefine PD? Introductory statement of the MDS Task Force on the definition of Parkinson's disease. Mov Disord. 2014;29(4):454-62.

4. Murdock C, Cousins W, Kernohan WG. Running Water Won't Freeze: how people with advanced Parkinson's disease experience occupation. Palliat Support Care. 2014;29:1-10.

5. Kim SR, Chung SJ, Yoo S. Factors contributing to malnutrition in patients with Parkinson's disease. Int J Nurs Pract. 2014 Dec 17. [Epub ahead of print]

6. Nytun JP, Fossum M. Information model for learning nursing terminology. Stud Health Technol Inform. 2014;205:181-5.

7. Kim TY, Hardiker N, Coenen A. Inter-terminology mapping of nursing problems. J Biomed Inform. 2014;49:213-20.

8. Tastan S, Linch GC, Keenan GM, Stifter J, McKinney D, Fahey L, et al. Evidence for the existing American Nursing Association: recognized standardized nursing terminologies: a systematic review. Int J Nurs Stud. 2014;51(8):1160-70.

9. NANDA International. Diagnósticos de enfermagem da NANDA: definições e classificação 2012-2014. Porto Alegre: Artmed; 2013.

10. Juvé Udina ME, Gonzalez Samartino M, Matud Calvo C. Mapping the Diagnosis Axis of an Interface Terminology to the NANDA International Taxonomy. ISRN Nurs. 2012:676905.

11. Hulley SB, Cumming SR, Browner WS, Grady DG, Hearst NB, Newman TB. Delineando a pesquisa clínica: uma abordagem epidemiológica. $3^{\mathrm{a}}$ ed. Porto Alegre: Artmed; 2008.

12. Connolly BS, Lang AE. Pharmacological treatment of Parkinson disease. JAMA. 2014;311(16):1670-83.

13. Fahn S, Jankovic J, Hallett M. Principles and practice of movement disorders. 2th ed. New York: Elsevier; 2011.

14. Robinson JP, Bradway CW, Bunting-Perry L, Avi-Itzhak T, Mangino M, Chittams J, et al. Lower urinary tract symptoms in men with Parkinson disease. J Neurosci Nurs. 2013;45(6):382-92.

15. Sakakibara R, Doi H, Sato M, Hirai S, Masaka T, Kishi M, et al. Nizatidine ameliorates slow transit constipation in Parkinson's disease. J Am Geriatr Soc. 2015;63(2):399-401.

16. Shin JY, Hendrix CC. Management of patients with Parkinson disease. Nurse Pract. 2013;38(10):34-43.

17. Ebersbach G, Moreau C, Gandor F, Defebvre L, Devos D. Clinical syndromes: Parkinsonian gait. Mov Disord. 2013;28(11):1552-9.

18. Barichella M, Cereda E, Madio C, lorio L, Pusani C, Cancello R, et al. Nutritional risk and gastrointestinal dysautonomia symptoms in Parkinson's disease outpatients hospitalised on a scheduled basis. Br J Nutr. 2013;110(2):347-53.

19. Ou R, Guo X, Wei Q, Cao B, Yang J, Song W, et al. Prevalence and clinical correlates of drooling in Parkinson disease: a study on 518 Chinese patients. Parkinsonism Relat Disord. 2014;16(14):476-3.

20. Erro R, Picillo M, Vitale C, Amboni M, Moccia M, Longo K, et al. Non-motor symptoms in early Parkinson's disease: a 2-year follow-up study on previously untreated patients. J Neurol Neurosurg Psychiatry. 2013;84(1):14-7.

21. Shin JY, Habermann B, Pretzer-Aboff I. Challenges and strategies of medication adherence in Parkinson's disease: a qualitative study. Geriatric Nurs. 2015 Feb 26. [Epub ahead of print] 